\title{
Budgeting and accounting of software cost: Part 2
}

\begin{abstract}
A. Seetharaman
is Associate Dean \& Chairman, Center for Multimedia Banking, Investment \& Accounting Center for Multimedia Banking, Investment \& Accounting, Faculty of Management, Multimedia University, Malaysia.
\end{abstract}

\section{Senthilvelmurugan}

is a part-time lecturer in IT at the Faculty of Management, Multimedia University, Malaysia.

\section{T. Subramanian}

is a lecturer in IT at the Faculty of Management, Multimedia University, Malaysia.

Keywords: costing systems, costing models, function point analysis, software development lifecycle

Abstract The first part of this paper surveyed the literature, reviewing trends in costing systems and costing models. This, the second and final part, deals in selected case studies, discussion, analysis and findings. The paper highlights the issues determining the size of software and how they relate to the accounting and budgeting of software cost through the estimation of various software metrics to empirically predict the cost involved before starting development. The paper also discusses how project and software costs are derived from the results obtained from the cost metrics. For this purpose, a practical six-step approach is derived and presented. Finally, the limitations are discussed and a conclusion is given.

\section{CASE STUDIES}

Heemstra and Kusters ${ }^{23}$ researched methods to justify cost-benefit for IT projects. The authors claimed that IT investment made up about 50 per cent of total expenditure and the cost-benefit ratio can be viewed from the following

63100 Cyber Jaya

Malaysia

Tel: +60 383125573

Email:

seetha@mmu.edu.my levels:

- application

- investment selection

- organization

Although the problem of investment in IT seems to exist at all levels, the measurement of IT at the organization level is the toughest. It was found that the software development cost formed only a fraction of the entire project cost, and surveys from other journals found that software maintenance cost was equal to development cost. The authors identified the current approaches to estimating software investment cost and then identified a framework containing the most relevant criteria that could be used in justifying the investment of software.

The authors provided a case study of cost-benefit risk (CBR) at the Dutch Department of Transport. Analyzing the results, the authors suggested that to optimize investment in software, 
stakeholders should be involved in the evaluation process. This offers better communication and ensures full cooperation from all parties involved.

The limitation of this survey was that although the authors suggested that stakeholders should be involved in the software evaluation process, this does not mean that the risk of high software investment could be reduced. Many other factors, not mentioned by the authors could also pose a threat to inflicting higher investment than usual for the software procurement.

Toffolon and Dakhli ${ }^{24}$ discussed issues pertaining to software reuse and how reusability of software components can drastically reduce the software development timeframe and indirectly reduce software cost. The authors indicated that many research papers that touch on software metrics do not cover the areas pertaining to the economics of software reuse. Hence, the authors wrote an excellent paper on how economics of software reuse could be used together with economic agency and transactions costs theories. The authors started their discussion on reevaluating software reuse and how this process is related to three economic models:
- cost avoidance (CA)

- return on investment (ROI)

- cost/benefit (CB)

The CA model tries to avoid cost during the software project. This reflects reality, as reusing software components will greatly reduce the development effort of the software and this will reduce the overall cost. The downside of this model, however, is the difficulty in predicting cost avoidance. In comparison, the ROI model uses the net present value (NPV) approach in predicting the long-term effect of software reuse. The CB model on the other hand, evaluates between cost and benefit ratio and is presented by the formula $\mathrm{R}=\mathrm{B} / \mathrm{C}$. Based on this approach, if the ratio yields a value of $\mathrm{R} 1$, then it would be justified in reusing the components for the software project, otherwise the benefit of the approach would be lost if cost (C) was larger than benefit (B). The authors proposed a three-level economic model for software reuse, ranging from the perspective of the three major management levels as denoted in Figure 4.

The authors proposed the use of the

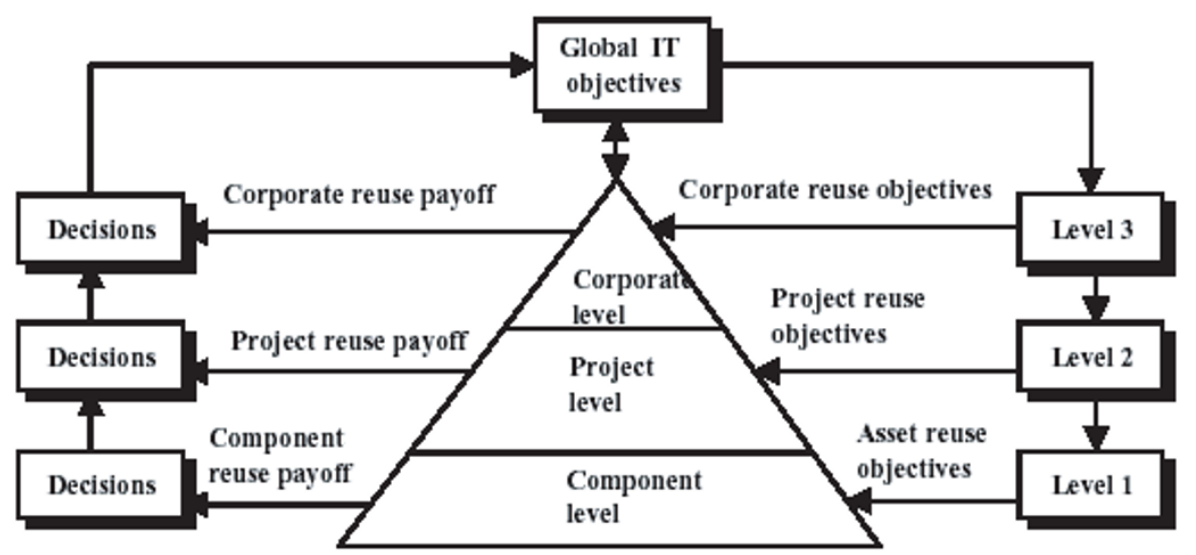

Figure 4: The three level economic model for software reuse proposed by Toffolon and Dakhli 
Tobit model (introduced by Tobin ${ }^{25}$ ) on how to estimate software reuse costsavings. The downside of this paper however was that the authors did not present any alternative prediction models to calculate the benefits of software reuse. Instead, they only used the Tobit model; whether this is the best approach is still unknown.

Maxwell and Forselius ${ }^{26}$ researched the cost factors in software maintenance cost. Their research involved an analysis of one commercial bank in Finland. Data were collected throughout the operations within the bank. These data were collected and stored within a central database. Defect statistics were also collected and were classified into 11 types and five categories. The information was statically analyzed using a stepwise analysis variance approach to determine which type and category had the highest variant. The result of maintenance cost allocation is denoted in Figure 5.

It can be seen that the securities trading system required the highest maintenance cost. This is due to the high overhead costs of high integration, interfacing and large batch processing. The rules and policies governing the securities system were very dynamic and this added to the cost of maintenance.
The payment systems had the lowest maintenance cost due to the fact that companies in Finland have a high level of automation with the banking system and all transactions are processed electronically, hence reducing maintenance cost significantly.

Unfortunately, this research was limited, as the maintenance cost factors were measured based on the environment of only one commercial bank. It would have been better if the authors had expanded the data to several banks, each having difference policies and types of information systems. Furthermore, the research was done for a bank in Finland. Banks in other countries function differently due to the rules and regulations governed by the country's central bank, hence this is another compelling reason that the software maintenance cost might differ as reported here.

Myrtveit and Stensrud ${ }^{27}$ discussed the effect of collecting historical data on software projects so that cost estimation would be compared with the suggested guidelines of the capability maturity model (CMM). CMM is a software engineering standard introduced by the Software Engineering Institute (SEI) at Carnegie Mellon University, which consists of five levels of software

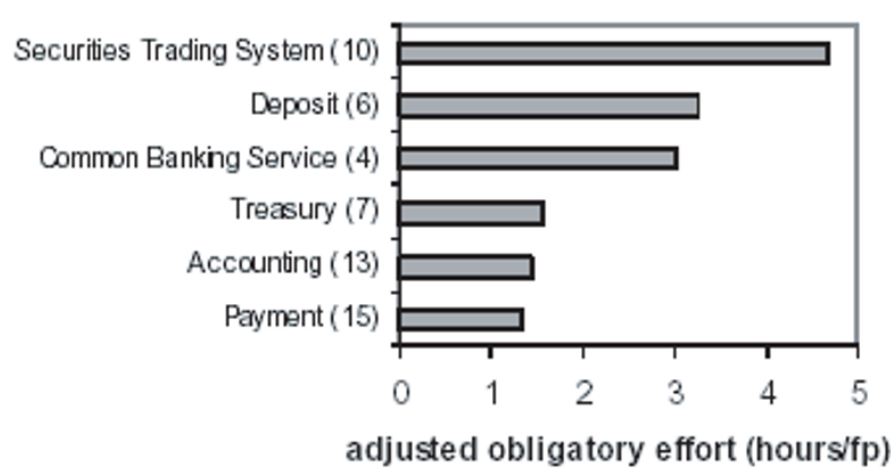

Figure 5: Annual maintenance hours per function point allocation 
maturity to which an organization can adapt.

The authors wanted to find out whether historical data collected together with experienced and nonexperienced project managers were able to provide better software cost estimation. The authors collected 48 sets of completed projects from within the same industry and allowed the project managers to estimate the cost of projects based on test metrics (Mean Magnitude of Relative Error [MMRE], Median Magnitude of Relative Error [MdMRE], Standard Deviation of Magnitude of Relative Error [SdMRE] or Maximum Magnitude of Relative Error [MaxMRE] were used).

The project managers were asked to estimate software cost based on those projects which had historical data against those that did not. The results were surprising. Whether or not historical data were used, the cost estimates were about the same. What mattered was the quality of historical data and the experience levels of the project managers. The more experienced project managers tended to ask intelligent questions that allowed them to predict cost estimation in a more efficient way.

A limitation of this research, however, was that the historical data were collected from within the same industry. Software built for different industries has different scopes and complexities. Hence, the authors should have taken a few samples from other industries to get more accurate results.

Morgan $^{28}$ wrote on controlling software development cost. The paper touched on issues pertaining to the variety of cost control practices and compared them with Japanese software developers where management accounting could be used to raise the productivity of the software development process.

The author proceeded to discuss the traditional software development cost controls and how these controls had inherent problems and risk. The author discussed how traditional management accounting could be used to reduce software cost. A technique known as target costing is used in the software development process. Target costing builds on the design approach for controlling the lifecycle cost rather than costs in production.

Morgan's paper was biased towards how Japanese developed software. The techniques used could be justifiable if a company wanting to adopt this approach has a similar management style. However, the author did not address this issue and assumed that all management can utilize this approach, which is considered a poor assumption.

Shareef and Ravichandran ${ }^{29}$ wrote a research paper on software process assessment via metric models. The research was done in India, through a company called SSI Technologies. The paper touched on measuring the critical elements of software activities during the development lifecycle of both process and product. The measurement was by collecting and analyzing data. The data were then put through a series of metrical formulae to determine the required effort to deliver the software project.

The authors divided the discussion into two areas: the development lifecycle of the software and the maintenance cost required for the software. For the former, the authors found that if the customer requirements specification was stabilized during the initial phase on the 
project lifecycle, there would be a decrease in the variance of budgeted versus actual efforts reported. The second justification was that the software would have fewer defects if it had been reviewed carefully in each stage of the development lifecycle. For the latter, the authors found that as the software application stabilized over a period of time, the maintenance cost is reduced proportionally. The authors did not provide comparison of their proposed methods with other cost metrics; the sample case was also very vague, hence encouraging the reader to make many assumptions.

\section{DISCUSSION, ANALYSIS AND FINDINGS}

Cost metrics were introduced to undermine the complexities of measuring the size and cost of software. In the early days of computing, software cost estimation was an $\operatorname{art}^{30}$ where competent project managers were able to deduce respectable estimates based on their vast experience. Again, the issue of "gut feeling" is brought up to justify its impact on the estimation process, which can have undesirable effects on the software project as a whole. Boehm et al., ${ }^{31}$ Albrecht $^{32}$ and Jones ${ }^{33}$ were a few pioneers to engineer cost estimation models for the software industry.

Many others derived cost metrics that were taken from the basic cost models like Lab On a Chip (LOC), Free of Particular Average (FPA), Commercial Off The Shelf (COTS) and

\section{COnstruction COst MOdel}

(COCOMO).

It was found that all cost metrics had one common objective, to predict the estimated efforts required to develop software in the most cost effective manner possible. This allowed project managers to predict software cost estimates with confidence and reduced the risk of projects delaying and overrunning their budget.

The usage of cost metrics has to be handled with utmost discipline, however. As noted by Myrtveit and Stensrud, ${ }^{34}$ cost metrics are useless if there are no quality historical data to benchmark against. To obtain and compile these historical data, a rigorous process of identifying and collecting quality data has to be started early. The more data collected, the more precise future cost estimates can be predicted. Poor quality data has an adverse effect on software cost predictions. It is akin to the common computer term "garbage in garbage out."

This paper has focused widely on the determination of software estimates. Unfortunately, all research papers presented in this paper were lacking on one issue: how to convert the estimated size and effort into monetary terms (ie cost).

There have been passionate debates on which cost metrics to use and what benefits they can provide for software projects in various situations. However, given that business decisions are based on accounting figures, it is important for a project manager to determine the actual cost of the project rather than the effort. This section will discuss the findings of how software cost can be derived from the efforts determined by using cost metrics like COCOMO 2. The example shown here is derived from a Malaysian software cost estimation perspective, hence the monetary term is shown in Malaysian ringgit (RM). The following is a 
guideline towards achieving this objective.

\section{Steps}

1. Use LOC, FPA or COCOMO to determine the estimated duration and efforts required. Adjusted function points are obtained after processing the unadjusted function points through a series of cost factors.

2. Determine the human resources required for the project team. Other costs to consider are efforts outsourcing cost to third-party software developers (contract workers).

3. Identify the cost for engaging the project team (eg salaries) and average them by reallocating the cost to roles within the project team.

4. Apply a cost index (CI) obtained from the accounts department. The cost index is to cater for indirect cost associated with the software cost of developing the software (eg of CI is $\mathrm{EPF}$, administration cost, depreciation of hardware, rental space, fixtures and furniture etc).

5. Apply risk mitigation ratio across the major milestones within the software project lifecycle.

6. Software cost is calculated and added to other operations costs to obtain the total project cost of the software.

\section{Step 1}

This step utilizes the software size estimation approaches using LOC or FPA. Although other estimation methods could be used, LOC and FPA have proven to provide accurate size predictions $^{35}$ (COCOMO $^{36}$ could also be used, as its underlying effort prediction engine is derived from FPA). By identifying the inputs required for FPA based on the scope of the software requirements, a project manager can derive the estimated efforts with penalty (EP). ${ }^{37}$ The EP can be processed with cost factors to derive the unadjusted efforts required to deliver the project. Software has the capacity to reuse predeveloped software components.

Software reusability can dramatically reduce the effort to deliver a software project. ${ }^{38,39}$ Hence to obtain the adjusted effort, the unadjusted effort should be processed by identifying patterns within the software that could reuse software components. ${ }^{40}$ The result is the adjusted effort that is used to determine the actual cost needed to develop the software.

For this example, it is assumed that to deliver this software, the adjusted effort required is 425 working man days, which is equal to 2,975 man hours, assuming one working man day has seven working hours.

Table 2: Project team

\begin{tabular}{lcl}
\hline Designations & Workers hired & Project role \\
\hline 1. Project manager & 1 & Project management \\
2. System analyst & 2 & Development \\
3. System designers & 3 & Development \\
4. Programmers & 10 & Development \\
5. Testers & 8 & Testing \\
6. Contract workers & 5 & Development \\
\hline
\end{tabular}


Table 3: Sample cost for hiring workers based on project role

\begin{tabular}{llll}
\hline Roles & Est. RM/month & Est. RM/day & Est. RM/hour \\
\hline Project management & $10,000.00$ & 454.55 & 64.94 \\
Development & $7,000.00$ & 318.18 & 45.45 \\
Testing & $5,000.00$ & 227.27 & 32.47 \\
\hline
\end{tabular}

One month $=22$ working days. Est. $=$ Estimated

1 day $=7$ hours

\section{Step 2}

The next step is to determine the number of people (for simplicity's sake, they will be called workers) who will be contributing to the development of the software. The workers can consist of project directors, project managers, systems analysts, system designers, programmers and testers. In this example, the workers listed in Table 2 are assumed to be hired to deliver the software project.

The workers will be allocated into their respective project roles by the project manager. In this example, three project roles are assumed. The project manager can allocate more roles if deemed necessary. This allocation is important to determine the cost needed for step 3 .

\section{Step 3}

The next step is to determine the average cost required for each role within the project. The major cost to identify is that of hiring the workers. Instead of calculating the cost of workers separately (some software projects have more than 500 developers), the accounting process can be simplified by averaging the cost based on project role. Table 3 denotes how this can be accomplished.

In this simple example, is it assumed that in one month, there are 22 working days. One day has seven hours allocated for working on the software. These variables can be decided by the project manager. In this example, the objective is to find the average cost of developing the software in hours as shown under the "Est. RM/hour" column. When deriving this cost, many assumptions are made. Indirect costs like Excess Pair Fraction (EPF), administration, rentals, fixtures and fittings, computer hardware depreciation and other costs are omitted. These overheads are covered by the cost index in Step 4.

\section{Step 4}

The cost index, obtained from the accounts department, will be derived by computing cost overheads from indirect costs incurred for the software that is being built. For the sake of

Table 4: Sample cost for hiring workers with adjusted cost after applying the cost index

\begin{tabular}{lllll}
\hline Roles & Est. RM/month & Est. RM/day & Est. RM/hour & Adj. RM/hour † \\
\hline Project management & $10,000.00$ & 454.55 & 64.94 & 129.87 \\
Development & $7,000.00$ & 318.18 & 45.45 & 90.91 \\
Testing & $5,000.00$ & 227.27 & 32.47 & 64.94 \\
\hline
\end{tabular}

$\dagger$ Adjusted cost 
Table 5: Risk mitigation ratio

\begin{tabular}{|c|c|c|c|c|}
\hline \multirow[b]{2}{*}{ Task } & \multirow[b]{2}{*}{$\begin{array}{l}\text { Timeline allocated } \\
\text { based on FPA } \\
\text { results (hours) }\end{array}$} & \multicolumn{3}{|l|}{ Ratio } \\
\hline & & $\begin{array}{l}\text { Project } \\
\text { management } \\
(\%)\end{array}$ & $\begin{array}{l}\text { Development } \\
\text { (\%) }\end{array}$ & $\begin{array}{l}\text { Testing } \\
(\%)\end{array}$ \\
\hline Analysis & 446 & 60 & 40 & 0 \\
\hline Database design & 148 & 20 & 80 & 0 \\
\hline System design & 179 & 20 & 80 & 0 \\
\hline Programming & 595 & 2 & 80 & 18 \\
\hline Database migration & 89 & 10 & 70 & 20 \\
\hline System testing & 893 & 5 & 15 & 80 \\
\hline Implementation & 208 & 30 & 30 & 40 \\
\hline Management & 417 & 100 & 0 & 0 \\
\hline Total & 2,975 & & & \\
\hline
\end{tabular}

simplicity, many software companies derive a cost index to be computed into the software cost to justify these costs. In many cases, an index of 1.8-2.5 is used, but for the example here, a value of 2.0 will be used. Thus, if applied to step 3, the adjusted cost per project role will be as shown in Table 4.

The actual cost per hour for one worker is as shown in Table 3. This is the cost per worker (in reference to the project role) that will be used in determining the software cost.

\section{Step 5}

In this step, the risk of developing the project is assessed. Risk assessment can be divided into the distinct areas of low, medium and high risk. Software projects that are considered low risk do not require much management and testing, however, for high-risk projects, allocating more budget to management and testing will significantly reduce the risk of failure.

In this example, the project will be considered as a high-risk project. The risk mitigation ratio is applied to the task breakdown within the project lifecycle. The allocation of cost here is based on the skills of the project manager. However, the project manager can still use the risk rule when faced with uncertainties. Table 5 shows the risk mitigation ratio and a sample task breakdown of the project.

The labor effort hours are split between this ratio - project management, development and testing - in order to calculate the cost for each task. Hence, the objective of this step is to obtain the risk mitigation ratio for each task.

\section{Step 6}

In the last step, the risk mitigation ratio is calculated against the cost of worker per project role; the cost allocation is shown in Table 6.

The cost of developing the software is estimated at RM226,539.61 or approximately RM227,000 with the cost breakdown for each project role. This approach also shows the total cost required for each task defined within the software development lifecycle. As this project is categorized as high risk, it is of 
Table 6: Cost allocation for each task

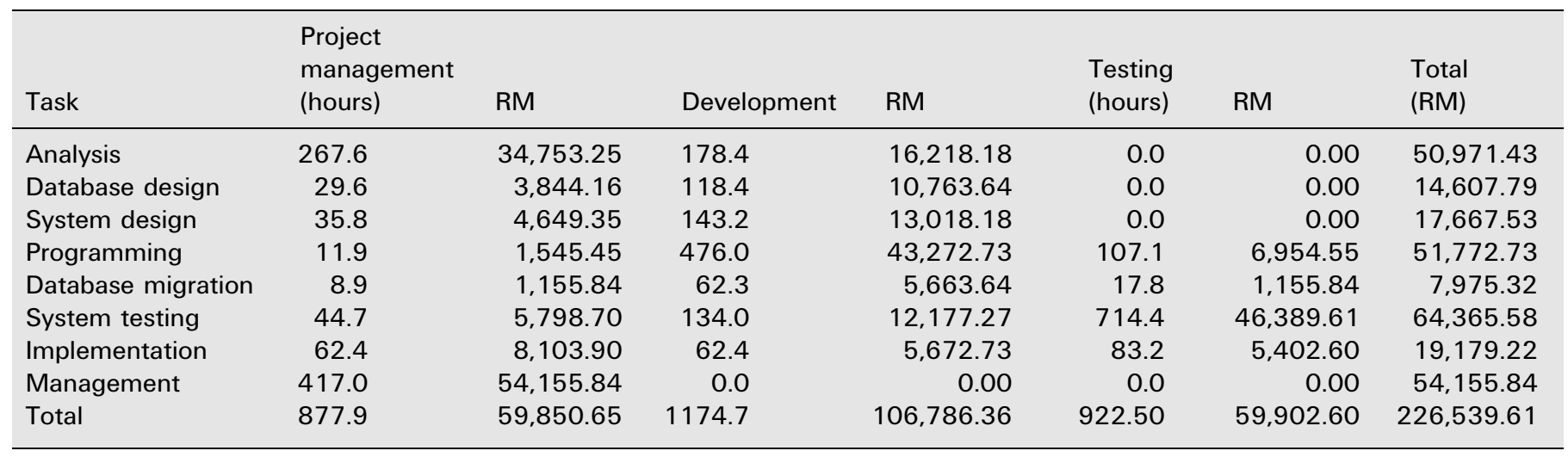

no surprise that the management and system testing tasks have been allocated the highest budgets. As proven, estimating the right efforts to deliver software projects influences the software cost, hence using the right cost metrics is important. Once the project manager has obtained the software cost, he can now determine the total project cost by including other external costs (hardware and other software costs) to be added to the software cost.

\section{LIMITATIONS}

As with other research papers, this paper has its limitations which can be classified as follows:

- All information presented in this paper was sourced from secondary data. There was no time to conduct a thorough survey on this topic and to get feedback from the software industry, in particular, the software industry in Malaysia.

- The research papers were all written by authors from other parts of the world. The authors tried to obtain some journals written about cost estimation in Malaysia, but were unsuccessful.

- This research paper is limited to the fundamentals of software cost estimation.
It does not undermine the complexities of cost metrics presented by other authors on this topic.

- The authors assume that the reader has some knowledge of software engineering and what purpose cost estimates provide within the software development lifecycle (SDLC).

- The method on how the cost index was derived was not shown. The authors had made the assumption that the index could have been derived from the accounts department or from a standard industrial index that is being practiced within a country.

- In the example shown in this paper, the total cost of the software project did not include maintenance costs.

- The derivation of software cost shown in this paper is by no means the best approach in determining software cost. A practical approach is proposed that could be used to justify software costing to both the customer and management.

\section{CONCLUSION}

There are many other approaches to software cost estimation that cannot fully be covered within this paper. Although there are numerous approaches, no one method is better 
than the others. ${ }^{41}$ Each cost model has its strong and weak points. There are some instances where a combination (hybrid) of the cost metrics is desirable to achieve a satisfactory benchmark for software costing. The mapping of labor effort to direct or indirect cost associated with the software project was neglected by all of these research papers. The authors have taken this limitation to show a practical approach on how software cost could have been derived from the results obtained from cost metrics. The approach was shown using simple accounting principles against labor efforts to develop software from a Malaysian software costing perspective.

\section{References}

23. Heemstra F.J. and Kusters, R.J. (2000) Assessing IT Investments: Costs, Benefits, Risks. European Software Control and Metrics. Available at: http:// www.escom.co.uk/conference2000/ index.shtml, last accessed January 2005.

24. Toffolon, C. and Dakhli, S. (1999) An Economic Model of Software Reuse. European Software Control and Metrics. Available at: http://www.escom.co.uk/ conference1999/index.shtml, last accessed January 2005.

25. See "The lifereg procedure 36.2 computing predicted value for a Tobit model," http://www.id.unizh.ch/ software/unix/statmath/sas/sasdoc/stat/ chap36/sect24.htm. Accessed August, 2005.

26. Maxwell K.D. and Forselius, P. (2001) Cost Drivers of Annual Maintenance: One Commercial Bank's Experience. European Software Control and Metrics. Available at: http://www.escom.co.uk/ conference2001/download.shtml, last accessed January 2005.
27. Myrtveit, I. and Stensrud, E. (1999) Does History Add Value to Project Cost Estimation? An Empirical Validation of a Claim in CMM. European Software Control and Metrics. Available at: http://www.escom.co.uk/ conference1999/index.shtml, last accessed January 2005.

28. Morgan, M.J. (1994) "Controlling software development cost," Industrial Management \& Data Systems, Vol. 94, No. 1, pp. 13-18.

29. Shareef, P M. and Ravichandran, S. (2001) Software Process Assessment through Metrics Models. European Software Control and Metrics. Available at: http://www.escom.co.uk/ conference2001/download.shtml, last accessed January 2005.

30. See ref 1 above.

31. See ref 6 above.

32. Albrecht, A.J. (1979) "Measuring applications development productivity" Proceedings of IBM Applic. Dev. Joint SHARE/GUIDE Symposium, Monterey, CA, pp. 83-92.

33. Jones, C. (1988) A Short History of Function Points and Feature Points. Software Productivity Research Inc., Technical paper, Cambridge, MA.

34. See ref 27 above.

35. See ref 17 above.

36. Boehm, B., Egyed, A., Kwan, J., Port, D., Shah, A. and Madachy, R. (1998) "Using the WinWin Spiral Model: A case study," IEEE Computer, July, pp. 33-44. Available at: http:// sunset.usc.edu/ aegyed/publications/ Using_the_WinWin_Spiral_Model_A_ Case_Study.pdf.

37. See ref 12 above.

38. See ref 17 above.

39. See ref 24 above.

40. See ref 12 above.

41. See ref 10 above. 